\title{
Author Correction: Identification and characterization of Cardiac Glycosides as senolytic compounds
}

Francisco Triana-Martínez, Pilar Picallos-Rabina (1), Sabela Da Silva-Álvarez, Federico Pietrocola, Susana Llanos (1), Verónica Rodilla (D), Enrica Soprano (D), Pablo Pedrosa, Alba Ferreirós (D), Marta Barradas (D), Fernanda Hernández-González, Marta Lalinde, Neus Prats, Cristina Bernadó, Patricia González, María Gómez, Maria P. Ikonomopoulou (D), Pablo J. Fernández-Marcos (1D), Tomás García-Caballero, Pablo del Pino (D), Joaquín Arribas, Anxo Vidal, Miguel González-Barcia, Manuel Serrano (1), María I. Loza, Eduardo Domínguez (1) \& Manuel Collado (10)

Correction to: Nature Communications https://doi.org/10.1038/s41467-019-12888-x, published online 21 October 2019.

The original version of this Article mistakenly included the following sentence in the Acknowledgement section:

P.P.-R. receives support from a program by the Deputacion de Coruña (BINV-CS/2019). This has now been corrected in both the PDF and HTML versions of the Article.

Published online: 16 September 2020

(c) Open Access This article is licensed under a Creative Commons Attribution 4.0 International License, which permits use, sharing, adaptation, distribution and reproduction in any medium or format, as long as you give appropriate credit to the original author(s) and the source, provide a link to the Creative Commons license, and indicate if changes were made. The images or other third party material in this article are included in the article's Creative Commons license, unless indicated otherwise in a credit

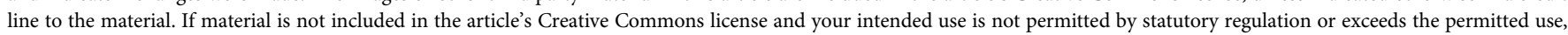
you will need to obtain permission directly from the copyright holder. To view a copy of this license, visit http://creativecommons.org/licenses/by/4.0/.

(C) The Author(s) 2020 